Chapter 11

\title{
Obesity and Heart Diseases, a Worsened Epidemic in Recent Decades
}

\author{
Jian-Lin Wu and Chi-Wen Juan \\ Additional information is available at the end of the chapter \\ http://dx.doi.org/10.5772/61044
}

\begin{abstract}
Overweight and obesity are major risk factors for a number of chronic diseases, including diabetes, cardiovascular diseases and metabolic diseases. Obesity induces serious heart diseases such as hypertension, heart failure, and coronary disease by multiple mechanisms. The endothelial dysfunction and artherosclerosis induced by obesity lead to the result of coronary artery disease. In addition, obesity is a substantial public health crisis worldwide, and internationally, with the prevalence increasing rapidly in numerous industrialized nations. Worldwide, $39 \%$ of adults aged 18 years and over were overweight in 2014, and 13\% were obese. The first choice of treatment is weight loss by life-style modification, such as diet and exercise. Medication and surgery are for moderate obese patients with comorbidity. How to find the appropriate method of weight losing is the most important issue.
\end{abstract}

Keywords: obesity, definition, coronary artery diseases, treatment, weight loss

\section{Introduction}

Obesity has become one of the most important public health issues due to the increased prevalence of the comorbidities associated with obesity. Recommendations, guidelines, and consensus statements for the definition and classification of obese children, adolescents, and adults have been published by many famous journal in these decades. Generally speaking, obesity is not only a major risk factors for a number of chronic diseases which mentioned above, but also a chronic disease that is increasing in prevalence in adults, adolescents, and children, and is now considered to be a global epidemic. 
The fundamental cause of obesity and overweight is an energy imbalance between calories consumed and calories expended. People travel on transportation, rather than walking, and so many people work in offices, where they are sitting still for most of the day. A sedentary lifestyle lowers calories expenditure. Eating excess calories with less consumption promotes weight gain. Of all sedentary behaviors, long-time TV watching appears to be the most predictive of obesity risk. In the Nurses' Health Study, after adjustment for age, smoking, exercise level, and dietary factors, every 2-hour increment spent watching TV was associated with a $23 \%(95 \%$ CI $17-30 \%)$ increase in obesity[1].

\section{Definition and classification}

- Overweight and obesity refer to a weight above the "normal" range.

We use body mass index (BMI)[BMI = body weight (in $\mathrm{kg}) \div$ height squared, in meters], which is currently used as the most accurate and reliable way of measuring how overweight an adult(18 years and older) is. For most people, an ideal BMI is between 18.5 and $24.9 \mathrm{~kg} / \mathrm{m}^{2}$. The classification is as follows:

- Underweight-BMI $<18.5 \mathrm{~kg} / \mathrm{m}^{2}$.

- Normal weight-BMI $\geq 18.5-24.9 \mathrm{~kg} / \mathrm{m}^{2}$.

- Overweight-BMI $\geq 25.0-29.9 \mathrm{~kg} / \mathrm{m}^{2}$.

- Obesity - BMI $\geq 30 \mathrm{~kg} / \mathrm{m}^{2}$.

- Obesity class I-BMI of $30.0-34.9 \mathrm{~kg} / \mathrm{m}^{2}$.

- Obesity class II-BMI of $35.0-39.9 \mathrm{~kg} / \mathrm{m}^{2}$.

- Obesity class III-BMI $\geq 40 \mathrm{~kg} / \mathrm{m}^{2}$. This type of obesity is also referred to as severe, extreme, or massive obesity.

Unfortunately, a strung healthy fitness instructor may be mistaken for an obese adult if we only use BMI to screen overweight and obesity. Because BMI cannot well describe the central fat accumulation in the abdomen, we use waist circumference as another measurement of obesity, especially abdominal obesity, and it provides risk information that is not accounted by BMI.A waist circumference of $\geq 40$ inches $(102 \mathrm{~cm}, 90 \mathrm{~cm}$ for Asian) for men and $\geq 35$ inches $(88 \mathrm{~cm}, 80 \mathrm{~cm}$ for Asian) for women is considered elevated and indicative of increased cardiovascular and metabolic disease risk [2].

Screening measures by BMI with waist circumference can identify adults at increased risk for morbidity and mortality, particularly in the BMI range $25-35 \mathrm{~kg} / \mathrm{m}^{2}[3]$.

For children, the different normal ranges of BMI are classified by age [4, 5]. A growing consensus supports the following definitions for children between 2 and 18 years of age

- Underweight $-\mathrm{BMI}<5$ th percentile for age and sex 
- Normal weight-BMI between the 5th and the 85th percentile for age and sex

- Overweight-BMI between the 85th and the 95th percentile for age and sex

- Obese-BMI $\geq 95$ th percentile for age and sex

- Severe obesity - BMI $\geq 120 \%$ of the 95 th percentile values, or a $B M I \geq 35 \mathrm{~kg} / \mathrm{m}^{2}$ (whichever is lower) $[6,7,8]$. This corresponds to approximately the 99th percentile, or BMI Z-score $\geq 2.33$ (e.g., 2.33 standard deviations above the mean) $[8,9,10]$. Some authors distinguish an additional subgroup with more severe obesity with $\mathrm{BMI} \geq 140 \%$ of the 95 th percentile values or a BMI $\geq 40 \mathrm{~kg} / \mathrm{m}^{2}$, which corresponds to class III obesity in adults $[7,8]$.

\section{Prevalence}

\section{- Adults}

Based on data collected for the National Health and Nutrition Examination Survey (NHANES) between 2011 and 2012, the measured prevalence of obesity in adults in the United States is $34.9 \%$ [11]. The age-adjusted prevalence of class III obesity (BMI $\geq 40$ ), sometimes referred to as severe obesity, was $6.3 \%$ in $2009-2010$ [12].Worldwide, 36.9\% of men and 38\% of women estimated to have a BMI $\geq 25 \mathrm{~kg} / \mathrm{m}^{2}[13,14]$. In 2013, reported prevalence rates of obesity (BMI of $\geq 30 \mathrm{~kg} / \mathrm{m} 2$ ) included $20 \%$ of men and $21.7 \%$ of women in Belgium, $25 \%$ of men and women in the United Kingdom, $21 \%$ of men and 33\% of women in Mexico, and $13.5 \%$ of men and $42 \%$ of women in South Africa [13,15].

\section{- Children}

Worldwide, 42 million children under the age of 5 years were overweight or obese in 2013.In the United States, the percentage of age of children aged 6-11 years in the United States who were obese increased from 7\% in 1980 to nearly 18\% in 2012. Similarly, the percentage of age of adolescents aged $12-19$ years who were obese increased from $5 \%$ to nearly $21 \%$ over the same period [16, 17].For example, Childhood obesity has more than doubled in children and quadrupled in adolescents in the past 30 years.

By reported data, the worldwide prevalence of obesity more than doubled between 1980 and 2014.Before, obesity was considered a high-income country problem due to stereotype about the relationship between money, the increased intake of energy-dense foods, and increase in physical inactivity. In fact, overweight and obesity are now on the rise in low- and middleincome countries, particularly in urban settings. In developing countries, the rate of increase of childhood overweight and obesity has been more than $30 \%$ higher than that of developed countries.

Changes in dietary and physical activity patterns are often the result of environmental and technical changes associated with economic development and lack of supportive policies in sectors such as health, urban planning, food processing, distribution, marketing, and education. 


\section{Pathogenesis and its related coronary artery disease}

Obesity has many causes, each of which has a variable genetic component. At one extreme are the kinds of obesity caused by single-gene mutations. At the other extreme are the kinds of obesity caused by various diseases in subjects in whom obesity would otherwise not occur. The followings focus on obesity caused by single-gene defects, the genetic susceptibility to obesity, and the pathogenetic mechanisms that operate within this genetic framework to cause differences in total body fat content and in regional fat distribution.

\section{Genetic disorders of obesity}

- Prader-Willi syndrome

The Prader-Willi syndrome is a neurodegenerative disorder that is caused by genetic abnormalities of the long (q) arm of chromosome 15 (15q11-q13).Affected infants have poor muscle tone and feed poorly at birth. Later their appetite becomes voracious and they become obese, have behavior problems (irritability, tantrums), delayed development, short stature, and, later, hypogonadotropic hypogonadism.

- Bardet-Biedl syndrome

The Bardet-Biedl syndrome is an autosomal recessive disorder characterized by obesity and several other abnormalities, including microorchidism in men, intellectual disability (mental retardation), retinal dystrophy, polydactyly, renal malformations (particularly calyceal abnormalities), and polyuria and polydipsia[18]. The primary cilia dysfunction is considered as a key defect in this syndrome [19].

\section{Genetic models of obesity}

- Leptin gene

The Lep gene codes for a protein called leptin [20]. Leptin-deficient mice have hyperphagia, insulin resistance, hyperinsulinemia, and infertility. In human, leptin is produced in fat cells and to a lesser degree in the gut [20]. It acts on leptin receptors (LEPRs), which are widely distributed and account for its pleiotropic effects on energy homeostasis, neuroendocrine function, and immune function [21].Food intake is reduced by systemic leptin administration in normal-weight experimental animals, but the response decreases as the animals become obese. The resistance to the action of leptin has been related to blunting the negative feedback signal to brain to reduce energy intake.

- Leptin receptor gene

The Leptin receptor (LEPR) deficiency has a relationship with human obesity. In a study, 3\% with severe, early-onset obesity had nonsense or missense LEPR mutations. Normal linear growth, but reduced adult height as adults and increased serum leptin concentrations were also observed $[22,23]$. 


\section{- Agouti gene}

The Agouti gene defect causes the Agouti-signaling protein overexpressed in many tissues. The Agouti protein competes with melanocyte-stimulating hormone (MSH) for a melanocortin-4 receptor in the hypothalamus that modulates food intake. MSH inhibits food intake. Food over-intake results from the blockage of MSH pathway by the agouti protein [24].

Other factors associated with the development of obesity, such as body fact distribution, diet, lifestyle, drugs, and endocrine disorders, have promote the dysregulation of fat and glucose metabolism. Now scientists understand that fat, especially intra-abdominal fat, has significant impact on blood pressure and blood lipid levels and interferes with the ability to use insulin effectively.

\section{Obesity and coronary artery disease}

In the past two decades, the growing development in vascular biology has been elucidating the nature of atherosclerotic lesions: they correspond to a series of cellular and molecular inflammatory responses [25, 26].

The coronary endothelial dysfunction is considered an early stage of the coronary arteriosclerosis. Arteriosclerosis develops through the influence of stress conditions to the endothelium, such as obesity, aging, systemic arterial high blood pressure,hypercholesterolemia, diabetes, and tobacco addiction. These factors damage the endothelium and induce an inflammatory reaction on the vascular wall. Such reaction increases the secretion of primary proinflammatory cytokines, such as interleukin (IL)-1 and tumor necrosis factor-alpha (TNF- $\alpha$ ) [27, 28].

In fact, adipose tissue is considered not only a deposition of triacylglycerol and free fatty acids but also an important endocrine and paracrine organ, which produces several proinflammatory substances [29]. An excess of adipose tissue indicates that obesity is being regarded as a source of proinflammatory mediators that contribute to vascular injury, insulin resistance, and atherogenesis. The adipokines, which play an important role of endothelium dysfunction and arteriosclerosis, include C-reactive protein (CRP), TNF- $\alpha$, angiotensinogen, resistin, leptin, IL-6, and plasminogen activator inhibitor-1 (PAI-1).

\section{Main inflammatory markers in obesity}

- C-reactive protein (CRP): The CRP is an acute phase protein (APP) synthesized in the liver and regulated by the circulating levels of IL-6. Recently, high levels of CRP in plasma were considered as independent predictors of coronary artery disease [30]. Circulating plasma levels of CRP are high in obese and are directly related to the amount of body fat, estimated by means of body mass index, visceral obesity, abdominal circumference, insulin resistance, metabolic syndrome, and diabetes mellitus [31].

- The CRP participates directly in the process of atherogenesis and modulates the endothelial function. It also induces the expression of several molecules (intercellular adhesion molecule-1 (ICAM-1), vascular cell adhesion molecule-1 (VCAM-1), monocyte chemoattractant protein-1 (MCP-1), and selectins). It acts as regulator of the production of nitric oxide in the endothelium and coordinates the production and secretion of several cytokines, increasing the proinflammatory activity of several adipokines [32]. 
- TNF- $\alpha$ : High amounts of secretion of inflammatory cytokine produced by obese individuals and by insulin-resistant patients not only give rise, but spread the formation of atherosclerotic lesion. The TNF- $\alpha$ participates in the acceleration of atherogenesis by inducing the expression of VCAM-1, ICAM-1, MCP-1, and E-selectin. It also reduces the bioavailability of nitric oxide in endothelial cells and impairs endothelium-dependant vasodilation, promoting the endothelial dysfunction. Besides this, it causes apoptosis in endothelial cells, contributing for endothelial injury [33].

- Resistin: It is a hormone specific of the adipose tissue recently discovered, which directly induces the insulin resistance in muscles and liver. The resistin induces the expression of messenger RNA producer of endothelin-1 in endothelial cells, thus contributing to endothelial dysfunction. It also significantly increases the expression of the cellular adhesion molecule VCAM-1 and the MCP-1, hey factors in formation of early atherosclerotic lesion [34]. It was recently demonstrated the proinflammatory action of resistin in smooth muscle cells: it induces the proliferation of such cells, suggesting the action of these hormones is restenosis of coronary lesions in patients with diabetes [35].

- Angiotensinogen: It is a precursor of angiotensin II, expressed and produced in adipocytes. The angiotensin II directly stimulates the expression of ICAM-1, VCAM-1, MCP-1, and MCSF in vascular cells. The increased production of angiotensinogen by the adipose tissue is associated with high blood pressure and angiogenesis, both related to endothelial dysfunction. Similarly, the angiotensin II acts in the formation of oxygen-derived free radicals, decreasing the availability of nitric oxide and causing damages to the vascular tissue [36].

- Adiponectin: Opposed to what happens to other adipokines already referred to, the levels of adiponectin are lower in obese patients, functioning as an inhibitor agent of the inflammatory process [37]. Clinical and experimental studies suggest that low levels of adiponectin contribute for the development of diseases related to obesity, including cardiovascular diseases [38]. Levels of adiponectin in plasma generally range from 3 to $30 \mu \mathrm{g} / \mathrm{ml}$ in healthy individuals. In obese individuals, these levels are significantly reduced, with negative correlation between BMI and adiponectin levels in plasma [39]. The reason for the reduction of the levels of adiponectin in obese individuals seem to be related with proinflammatory cytokines, such as the IL-6, which, due to the fact they increase in obese individuals, may cause a reduction in the expression of the messenger RNA producer of adiponectin and its release by adipocytes [40]. In vascular levels, actions of the adiponectin comprise reduction in expression of ICAM-1, VCAM-1, and E-selectin.

\section{Obesity and its related heart disease}

Obesity increases total blood volume and cardiac output, and cardiac workload is greater in obesity. Typically, obese patients have a higher cardiac output but a lower level of total peripheral resistance at any given level of arterial pressure. With increased filling pressure and volume, overweight and obese individuals often develop left ventricular (LV) chamber dilation and the risk of left ventricular hypertrophy also increases [41]. In addition to LV 
structural abnormalities, obesity also leads to left atrial enlargement, both from increased circulating blood volume as well as abnormal LV diastolic filling [42]. These abnormalities not only increase the risk of heart failure, but may increase the risk of atrial fibrillation.

- Obesity and hypertension

A study [43] showed that activation of the sympathetic nervous system has been considered to have an important function in the pathogenesis of obesity-related hypertension. Plasma renin activity, angiotensinogen, angiotensin II, and aldosterone values display significant increase during obesity. Insulin resistance and inflammation may promote an altered profile of vascular function and consequently hypertension. Leptin and other neuropeptides are possible links between obesity and the development of hypertension.

The arterial pressure control mechanism of diuresis and natriuresis, according to the principle of infinite feedback gain, seems to be shifted toward higher blood pressure levels in obese individuals.

- Obesity and Heart failure

A study of 5,881 Framingham Heart Study participants [44] showed that during a 14-year follow-up, heart failure developed in 496 participants (258 women and 238 men). The crude cumulative incidence and the age-adjusted incidence rates of heart failure increased across categories of body mass index for both men and women. For every $1 \mathrm{~kg} / \mathrm{m}^{2}$ increment in BMI, the risk of heart failure increased 5\% in men and $7 \%$ in women. In fact, a graded increase in the risk of HF was observed across all categories of BMI.

The strength of the association, the stepwise increase in the risk of heart failure across increasing categories of body mass index, the demonstration of a temporal sequence (with increased body mass index preceding the development of heart failure), and the consistency of results in multiple analyses suggest a causal relation between increased body mass index and heart failure.

\section{Obesity and arrhythmias}

- Atrial fibrillation (Af)

The mechanisms linking atrial fibrillation and obesity include: structural and electrophysiological atrial remodeling, metabolic factors, sympathovagal imbalance, clinical links (obstructive sleep apnea, cardiovascular comorbidities) and inflammation.

Based on a population-based cohort studies [45], obese individuals have an associated $49 \%$ increased risk of developing Af compared to non-obese individuals (relative risk 1.49, 95\% confidence interval 1.36-1.64). The risk of atrial fibrillation increased in parallel with greater BMI in this cohort. Thus, Af evolves as yet another pathogenic factor by which obesity may increase cardiovascular and cerebrovascular events. In contrast, in the postcardiac surgery studies, obese individuals do not have an associated increased risk of developing Af compared to non-obese individuals (relative risk 1.02, 95\% confidence interval 0.99-1.06) [45]. 
- Ventricular arrhythmias

The another commonly reported arrhythmias resulting from obesity is ventricular tachycardia. The main mechanisms leading to ventricular arrhythmia and sudden cardiac death in obese individuals include cardiomyopathy, metabolic factors, sympathetic hyperinnervation, obesity-induced electrophysiological remodeling, coronary heart disease as common comorbidity and radical weight reduction strategies. Electrocardiographic monitoring, including $\mathrm{P}$ wave and QT interval duration, are extremely important in obese patients [46].

A positive association between corrected QT (QTc) interval and BMI has been noted, and prolonged QTc has predicted increased mortality even in apparently healthy populations. Although a relationship between QTc and increased obesity has been noted in many studies, this is most evident in the severely obese [47]. The presence of late potentials may be related to some of the pathological changes noted with cardiomyopathy of obesity, including myocyte hypertrophy, fibrosis, and fat. Finally, obesity is associated with abnormalities in sympathovagal balance, leading to higher heart rate and reduced heart rate variability, known factors related with increased risk of sudden cardiac death (SCD).

Overwhelming evidence supports the importance of obesity in the pathogenesis and progression of heart diseases, with increased indexes of morbidity and mortality. If the obesity epidemic continues, human may soon witness an unfortunate end in life.

\section{Evaluation}

\section{Determine etiology}

Many factors contribute to obesity. However, most cases of obesity are related to factors such as a sedentary lifestyle and increased caloric intake [48].

To determine etiology, the medical history should include age at onset and duration of weight gain, any habit change and events associated with weight gain, previous weight loss attempts, change in dietary patterns, exercise, current and past medications, and history of smoking. Medications are a common cause of weight gain and obesity, in particular insulin, sulfonylureas, thiazolidinediones, and antipsychotics agent.

Physical examination should focus on the possible secondary cause of obesity, including thyroid goiter (hypothyroidism), proximal muscle weakness, purple striae, osteoporosis (Cushing's syndrome), and acne/hirsutism. The related vital sign change (e.g., Blood pressure and heart rate) and testing (e.g., laboratory tests) to assess other metabolic diseases associated with obesity are also important to evaluate overweight and obese individuals.

\section{Assessment of risk}

To assess an individual's risk for subsequent mortality, the degree of overweight (BMI) and the presence of abdominal obesity (waist circumference), cardiovascular risk factors, comorbidities, and other factors should be measured. 


\section{- Cardiovascular risk factors}

Risk factors for CVD include high blood pressure (hypertension) and smoking, dysregulation of blood cholesterol (reduced levels of high-density lipoprotein [HDL] or elevated levels of low-density lipoprotein [LDL]), diabetes, sleep apnea, lack of exercise, family history of heart disease, and ethnic background. These risk factors should be managed independent of weight loss efforts.

- Comorbidities and other factor

- Symptomatic osteoarthritis: The disease is associated with obesity that do not increase cardiovascular risk. The precise mechanism by which obesity leads to osteoarthritis remains unknown but is likely to be due to a combination of mechanical, humoral, and genetic factors. Weight loss has clear medical benefits for the obese patient and seems to be a logical way of relieving joint pain associated with degenerative arthritis [49].

- Pregnancy: Women have more fat as a percent of body weight than men from puberty onward and tend to gain more fat during adult life than men. Being overweight increases the risk of complications for pregnant women and their babies. The higher a woman's $\mathrm{BMI}$, the higher the risks. The increasing risks are in relation to: gestational diabetes and miscarriage, high blood pressure and preeclampsia, blood clots, and having a baby weighing more than $4 \mathrm{~kg}$.

- Age of onset: Children with a low birth weight and those whose weight rises more rapidly in the first 10 years are at high risk for diabetes as adults [50].

\section{Treatment}

The goal of treatment for obesity is to lose weight in order to improve your health, both physically and psychologically. For example, losing weight may help you to improve your self-esteem or help you to decrease the risk of coronary artery disease.

Types of treatment-Based on patient's measurements and medical history, doctor or nurse can determine what combination of weight loss treatments would work best. Treatments may include changes in lifestyle, exercise, dieting and, in some cases, weight loss medicines or weight loss surgery.

- Importance of weight loss

The importance of weight loss in obese subjects is that obesity is associated with many health risks, including hypertension, heart failure, coronary artery disease, dyslipidemia, and diabetes.The higher the BMI and waist circumference, the greater the risk.

One study indicated that overweight/obese women with obesity-related illness, who lost weight intentionally within 1 year, had significantly reduced mortality rates of $19-25 \%$. In contrast, studies of overweight/obese diabetics irrespective of gender showed significant 
benefit of intentional weight loss on mortality in a meta-analysis, hazard ratios $=0.75(0.67-$ $0.83)[51]$.

\section{- Treatment options}

It is important to set goals when discussing a weight loss program with an individual patient. Many nervous patients have a weight loss goal of $40 \%$ or more below current weight, which is unrealistic. A realistic weight loss goal will make a better initial point. An initial weight loss goal of $5-7 \%$ of body weight is realistic for most individuals [52].A weight loss of more than $5 \%$ can reduce risk factors for cardiovascular disease, such as dyslipidemia, hypertension, and diabetes mellitus [53]. In trials comparing pharmacologic therapy with placebo, weight loss of $10-15 \%$ using both drug and behavioral intervention is considered a very good response, and weight loss exceeding 15\% is considered an excellent response. Thus, the clinician and the patient need to come to a mutual understanding of the realities of weight loss.

Individuals with a BMI of $25-29.9 \mathrm{~kg} / \mathrm{m}^{2}$, who do not have risk factors for cardiovascular disease or other obesity related comorbidities, may be described as having low risk. They should receive counseling on prevention of weight gain. Individuals with a BMI between 25 and $29.9 \mathrm{~kg} / \mathrm{m}^{2}$ and with one or more risk factors for CVD (diabetes, hypertension, and dyslipidemia), or with a BMI of $30-34.9 \mathrm{~kg} / \mathrm{m}^{2}$, are at moderate risk. They should be counseled about weight loss interventions.

- Types of treatment

- Changes in lifestyle: lifestyle modification is the most essential and gentle method of body weight loss. It is also physician's first choice. A comprehensive lifestyle intervention (combined diet, exercise, and behavioral treatment) is the most important strategy for weight management. The behavioral component facilitates adherence to diet and exercise regimens. It includes regular self-monitoring of food intake, physical activity, and body weight. Some behavioral components were used to help achieve these weight loss goals, including behavioral self-management training, individual case managers, group and/or individual sessions, individualized adherence strategies, and a network of training, feedback, and clinical support [54].

- Exercise and dietary therapy: Exercise and dietary therapy remain essential to the treatment of obesity, even for patients who choose medications or surgery. In most studies, exercise modestly improves weight loss and show an association between higher levels of physical activity and lower rates of many chronic diseases, such as obesity [55]. The multicomponent exercise program should be designed to prevent the possibility of exercise injury and to fit individuals, who can receive a pre-exercise evaluation by physicians. A well-designed exercise program should include balanced training and flexibility, and aerobic exercise and high-intensity resistance training may be effective. The duration and the energy expenditure goal should also fit individuals.

The goal of dietary therapy is to reduce the calories consumed. Balanced low-calorie diets/ portion-controlled diets with low-fat diets and low-carbohydrate diets are the components of the commonly used dietary therapy to reach the goal of calories restriction. However, the overor rapid decrease of calories may lead to side effects such as mentioned below. 


\section{Weight loss medicines or weight loss surgery}

Drug therapy is not the first choice, but it is recommended for patients with a BMI greater than $30 \mathrm{~kg} / \mathrm{m}^{2}$, or a BMI of $27-29.9 \mathrm{~kg} / \mathrm{m}^{2}$ if they have comorbid conditions, such as hypertension, heart failure, coronary artery disease, diabetes, etc.

- Orlistat, as the drug to alter fat digestion, has cardiovascular safety and beneficial effects on serum total cholesterol and low-density lipoprotein concentrations. The recommended dose for patients who are candidates for pharmacologic therapy is $120 \mathrm{mg}$ three times per day. Orlistat does not alter the pharmacokinetics of many drugs. However, absorption of fatsoluble vitamins may be decreased by orlistat. Patients with orlistat therapy should be advised to take a multivitamin. For patients taking warfarin, a decrease in vitamin K may be related to a higher bleeding tendency.Reduction in the dose of warfarin with INR regular monitor are recommended.

- Lorcaserin, as the drug of serotonin agonist, is approved as an addition to a reduced-calorie diet and exercise for patients who are obese (BMI $\geq 30 \mathrm{~kg} / \mathrm{m}^{2}$ ) or overweight (BMI $\geq 27$ $\mathrm{kg} / \mathrm{m}^{2}$ ) with at least one medical comorbidity, such as type 2 diabetes, hypertension, heart failure, dyslipidemia, or sleep apnea [56, 57]. Lorcaserin appears to have similar efficacy as and fewer adverse effects than orlistat, although long-term safety data are limited.

- Diabetes drugs, such as metformin, exenatide, and liraglutide, are suitable for diabetic patients with obesity. In one trial of patients with obesity and the metabolic syndrome, patients receiving metformin lost significantly more weight $(1-2 \mathrm{~kg})$ than the placebo group [58]. The weight loss efficacy of the other two drugs, as GLP-1 receptor agonists, has been reported in trials. In the United State, liraglutide is available for diabetic patients with body mass index (BMI) $\geq 30 \mathrm{~kg} / \mathrm{m}^{2}$ or $\geq 27 \mathrm{~kg} / \mathrm{m}^{2}$ with at least one obesity related comorbidity.

- Combination drugs: Phentermine-topiramate combination was compared with placebo in 2487 adults with BMI of $27-45 \mathrm{~kg} / \mathrm{m}^{2}$ and two or more comorbidities [59]. After 1 year, mean weight loss was greater in those assigned to treatment (8-10\% versus $1.4 \mathrm{~kg}$ with placebo [ $8-10 \%$ versus $1.2 \%$ of baseline bodyweight]). Unfortunately, the combination was less effective in further weight loss in the second year.

- Bariatric surgery is only considered for patients with BMI $\geq 40 \mathrm{~kg} / \mathrm{m}^{2}$ who have "failed" to lose weight with diet, exercise, and drug therapy.

- Risks of treatment-treatments for obesity can be divided according to the risk of side effects.

- The side effects of orlistat include intestinal borborygmi and cramps, flatus, fecal incontinence, oily spotting, and flatus with discharge.

- In clinical trials $[44,45]$, the most common side effect of lorcaserin was headache, experienced by about $18 \%$ of drug arm participants compared to $11 \%$ of placebo participants. The other side effects are as follows: upper respiratory tract infection (14.8\% vs. $11.9 \%)$, sinusitis (7.2\% vs. $8.2 \%)$, and nausea (7.5\% vs. $5.4 \%)$.

- The most common adverse events verse placebo in these trials of phentermine-topiramate combination were dry mouth (13-21\%vs. $2 \%$ ), constipation (15-17\% versus $6 \%$ ), and paresthesia (14-21\%vs. 2\%) [59]. 
- The most common adverse effects of bariatric surgery were iron deficiency anemia and the need for reoperations.

\section{Conclusion}

The general consensus is that excess intake of calories from any source and physical inactivity, associated with a sedentary lifestyle, causes weight gain and obesity. The strong evidences from trials, studies, and guidelines have been reported that obesity and its related comorbidity increase the risk of mortality. The benefits of weight loss are also seen. However, it is not good enough to just decrease body weight.

A well-designed weight loss program for individuals includes the weight loss goal, preexercise evaluation, exercise program, diet therapy, and the adequate medication - "Right drug, Right does, Right population" for these obese patients with comorbidities.

Even though obesity increases prevalence year by year, we must look forward to the challenge of reversing this epidemic and have confidence in our future.

\section{Appendices and nomenclatures}

Waist circumference measurement sites:

1. Locate upper hip bone and top of right iliac crest.

2. Place measuring tape in horizontal plane around abdomen at iliac crest.

3. Ensure tape in sung but does not compress the skin.

4. Tape should be parallel to floor.

5. Record measurement at the end of a normal expiration.

\section{Author details}

Jian-Lin $\mathrm{Wu}^{1}$ and Chi-Wen Juan ${ }^{1,2^{*}}$

*Address all correspondence to: juanchiwen@yahoo.com.tw

1 Department of Family Medicine, Kuang Tien General Hospital, Taichung, Taiwan

2 Department of Nursing, Hung Kuang University, Taichung, Taiwan 


\section{References}

[1] Hu FB, Li TY, Colditz GA, et al. Television watching and other sedentary behaviors in relation to risk of obesity and type 2 diabetes mellitus in women. JAMA 2003; 289: 1785.

[2] Jensen MD, Ryan DH, Apovian CM, et al. 2013 AHA/ACC/TOS guideline for the management of overweight and obesity in adults: a report of the American College of Cardiology/American Heart Association Task Force on Practice Guidelines and The Obesity Society. Circulation 2014; 129:S102.

[3] Jensen MD, Ryan DH, Apovian CM, et al. 2013 AHA/ACC/TOS guideline for the management of overweight and obesity in adults: a report of the American College of Cardiology/American Heart Association Task Force on Practice Guidelines and The Obesity Society. Circulation 2014; 129:S102.

[4] Ogden CL, Carroll MD, Kit BK, Flegal KM. Prevalence of childhood and adult obesity in the United States, 2011-2012. JAMA 2014; 311(8):806-814.

[5] Strauss RS, Pollack HA. Epidemic increase in childhood overweight, 1986-1998. JAMA 2001; 286: 2845.

[6] Kelly AS, Barlow SE, Rao G, et al. Severe obesity in children and adolescents: identification, associated health risks, and treatment approaches: a scientific statement from the American Heart Association. Circulation 2013; 128: 1689.

[7] Skinner AC, Skelton JA.Prevalence and trends in obesity and severe obesity among children in the United States, 1999-2012. JAMA Pediatr 2014; 168: 561.

[8] Kelly AS, Barlow SE, Rao G, et al. Severe obesity in children and adolescents: identification, associated health risks, and treatment approaches: a scientific statement from the American Heart Association.Circulation 2013.

[9] Flegal KM, Wei R, Ogden CL, et al. Characterizing extreme values of body mass index-for-age by using the 2000 Centers for Disease Control and Prevention growth charts.Am J ClinNutr 2009;90:1314.

[10] Gulati AK, Kaplan DW, Daniels SR. Clinical tracking of severely obese children: a new growth chart. Pediatrics 2012; 130: 1136.

[11] Ogden CL, Carroll MD, Kit BK, Flegal KM. Prevalence of childhood and adult obesity in the United States, 2011-2012. JAMA 2014; 311: 806.

[12] Centers for Disease control and Prevention, Overweight and Obesity. http:// www.cdc.gov/obesity/data/adult.html (accessed on September 09, 2013)

[13] Ng M, Fleming T, Robinson M, et al. Global, regional, and national prevalence of overweight and obesity in children and adults during 1980-2013: a systematic analysis for the Global Burden of Disease Study 2013. Lancet 2014; 384: 766. 
[14] Swinburn BA, Sacks G, Hall KD, et al. The global obesity pandemic: shaped by global drivers and local environments. Lancet 2011; 378: 804.

[15] International Association for the Study of Obesity http://www.iaso.org/resources/ world-map-obesity/ (accessed on February 06, 2014).

[16] Ogden CL, Carroll MD, Kit BK, Flegal KM. Prevalence of childhood and adult obesity in the United States, 2011-2012. JAMA 2014; 311(8):806-814.

[17] Skinner AC, Skelton JA. Prevalence and trends in obesity and severe obesity among children in the United States,1999-2012.JAMA Pediatr 2014.

[18] Parfrey PS, Davidson WS, Green JS.Clinical and genetic epidemiology of inherited renal disease in Newfoundland. Kidney Int 2002; 61: 1925.

[19] Marion V, Stoetzel C, Schlicht D, et al. Transient ciliogenesis involving Bardet-Biedl syndrome proteins is a fundamental characteristic of adipogenic differentiation. ProcNatlAcadSci U S A 2009; 106: 1820.

[20] [20]Dardeno TA, Chou SH, Moon HS, et al.Leptin in human physiology and therapeutics. Front Neuroendocrinol 2010; 31: 377.

[21] Procaccini C, Jirillo E, Matarese G. Leptin as an immunomodulator. Mol Aspects Med 2012; 33: 35.

[22] Clément K, Vaisse C, Lahlou N, et al. A mutation in the human leptin receptor gene causes obesity and pituitary dysfunction. Nature 1998; 392: 398.

[23] Farooqi IS, Wangensteen T, Collins S, et al. Clinical and molecular genetic spectrum of congenital deficiency of the leptin receptor. N Engl J Med 2007; 356: 237.

[24] Mountjoy KG. Functions for pro-opiomelanocortin-derived peptides in obesity and diabetes.Biochem J 2010; 428: 305.

[25] Rocha VZ, Libby P.Obesity,inflammation, and atherosclerosis.Nat Rev Cardiol. 2009; 6 (6): 399-409.

[26] Serrano CV Jr, Souza JA, Paiva MSMO. Fatoresdesencadeantes da instabilização da placaaterosclerótica.RevSocCardiol Estado de São Paulo.2001; 4: 724-32.

[27] Fernandes JL, Soeiro A, Ferreira CB, Serrano CV Jr. Síndromescoronáriasagudas e inflamação. Rev SocCardiol Estado de São Paulo.2006; 3: 178-87.

[28] Serrano CV Jr, Souza JA, Heinisch RH.Aagressão vascular no desencadeamento das síndromesisquêmicasmiocárdicasinstáveis. In: Nicolau JC, Marin JA.(eds.). Síndromesisquêmicasmiocárdicasinstáveis. São Paulo: Atheneu; 2001. p. 25-36.

[29] Mazurek T, Zhang L, Zalewski A. Human epicardial adipose tissue is a source of inflammatory mediators.Circulation.2003;108;2460-6. 
[30] Ridker PM. Clinical application of C-reactive protein for cardiovascular disease detection and prevention.Circulation.2003; 107: 363-9.

[31] Pasceri V, Willerson JT, Yeh ET. Direct proinflammatory effect of C-reactive protein on human endothelial cells. Circulation 2000; 102: 2165-8.

[32] Lemieux I, Pascot A, Prud'home D, Alméras N, Bogaty P, Nadeau A, et al. Elevated C-reactive protein: another component of the atherothrombotic profile of abdominal obesity. ArteriosclerThrombVasc Biol.2001; 21:961-7.

[33] Hotamisligil G, Arner P, Caro JF, Atkinson RL, Spiegelman BM. Increased adipose tissue expression of tumor necrosis factor-alpha in human obesity and insulin resistence. J Clin Invest.1995; 95: 2409-15.

[34] Steppan CM, Bailey ST, Bhat S, Brown EJ, Banerjee RR, Wright CM, et al. The hormone resistin links obesity to diabetes. Nature.2001; 409: 307-12.

[35] Calabro P, Samudio I, Willerson JT, Yeh ET. Resistin promotes smooth muscle cell proliferation through activation of extracellular signal-regulated kinase $1 / 2$ and phosphatidylinositol 3-kinase pathways. Circulation.2004; 10: 3335-40.

[36] Tham DM, Martin-McNulty B, Wang YX, Wilson DW, Vergona R, Sullivan ME, et al. Angiotensin II is associated with activation of NF-B-associated genes and downregulation of PPARs. Physiol Genomics.2002; 11: 21-30.

[37] Hopkins T, Ouchi N, Shibata R, Walsh K. Adiponectin actions in the cardiovascular system. Cardiovasc Res.2007; 74: 11-8.

[38] Arita Y, Kihara S, Ouchi N, Takahashi M, Maeda K, Miyagawa J, et al. Paradoxical decrease of an adipose-especific protein, adiponectin, in obesity. BiochemBiophys Res Commun.1999; 270: 79-83.

[39] Ouchi N, Kihara S, Funahashi T. Obesity, adiponectin and vascular inflammatory disease. CurrOpin Lipidol.2003; 14: 561-6.

[40] Ouchi N, Kihara S, Arita Y, Okamoto Y, Maeda K, Kuriyama H, et al. Adiponectin, an adipocyte-derived plasma protein, inhibits endothelial NFkappaB signaling through a cAMP-dependent pathway. Circulation.2000; 102: 1296-301.

[41] Carl J. Lavie, MD, Richard V. Milani, MD, Hector O. Ventura, MD. Obesity and Cardiovascular Disease: Risk Factor, Paradox, and Impact of Weight Loss doi:10.1016/ j.jacc.2008.12.068.

[42] Alpert MA. Obesity cardiomyopathy: pathophysiology and evolution of the clinical syndrome Am J Med Sci 2001; 321: 225-236.

[43] Kotsis VI, Stabouli S, Papakatsika S, Rizos Z, Parati G. Mechanisms of obesity-induced hypertension. Hypertens Res. 2010 May; 33(5):386-93. doi: 10.1038/hr.2010.9. 
[44] Kenchaiah S, Evans JC, Levy D, et al. Obesity and the risk of heart failure N Engl J Med 2002; 347: 305-313.

[45] Wanahita N, Messerli FH, Bangalore S, et al. Atrial fibrillation and obesity-results of a meta-analysis Am Heart J 2008; 155: 310-315.

[46] [46]Mozos I.Arrhythmia risk and obesity.J Mol Genet Med 2014: S1.

[47] el-Gamal A, Gallagher D, Nawras A, et al. Effects of obesity on QT, RR, and QTc intervals. Am J Cardiol 1995;75: 956-959.

[48] Tsai AG, Wadden TA. In the clinic: obesity. Ann Intern Med 2013; 159:ITC3.

[49] Sridhar MS, Jarrett CD, Xerogeanes JW, Labib SA.Obesity and symptomatic osteoarthritis of the knee. J Bone Joint Surg Br. 2012 Apr; 94(4):433-40. doi: 10.1302/0301-620X.94B4.27648.

[50] [50]Bhargava SK, Sachdev HS, Fall CH, et al. Relation of serial changes in childhood body-mass index to impaired glucose tolerance in young adulthood.N Engl J Med 2004; 350:865.

[51] Poobalan AS, Aucott LS, Smith WC, et al. Long-term weight loss effects on all cause mortality in overweight/obese populations. Obes Rev 2007; 8:503.

[52] National Institutes of Health, National Heart, Lung, and Blood Institute. The Practical Guide: Identification, Evaluation, and Treatment of Overweight and Obesity in Adults. NIH Publication Number 00-4084, October 2000. http://www.nhlbi.nih.gov/ guidelines/obesity/prctgdc.pdf (accessed on December 05, 2011).

[53] Diabetes Prevention Program (DPP) Research Group. The Diabetes Prevention Program (DPP): description of lifestyle intervention. Diabetes Care 2002; 25:2165.

[54] Douketis JD, Macie C, Thabane L, Williamson DF. Systematic review of long-term weight loss studies in obese adults: clinical significance and applicability to clinical practice. Int J Obes (Lond) 2005; 29:1153.

[55] Physical Activity Guidelines Advisory Committee.Physical Activity Guidelines Advisory Committee Report, 2008.US Department of Health and Human Services, Washington, DC, 2008.

[56] FDA News and Events: FDA approves Belviq to treat some overweight or obese adults (accessed on June 29, 2012). http://www.fda.gov/NewsEvents/Newsroom/ PressAnnouncements/ucm309993.htm?utm_campaign=Google2\&utm_source=fdaSearch\&utm_medium $=$ website\&utm_term $=$ lorcaserin\&utm_content $=4$

[57] FDA Highlights of Prescribing Information: BELVIQ (lorcaserin hydrochloride) tablets, for oral use (accessed on September 17, 2012). http://www.accessdata.fda.gov/ drugsatfda_docs/label/2012/022529lbl.pdf 
[58] Fontbonne A, Charles MA, Juhan-Vague I, et al. The effect of metformin on the metabolic abnormalities associated with upper-body fat distribution. BIGPRO Study Group. Diabetes Care 1996; 19: 920.

[59] Gadde KM, Allison DB, Ryan DH, et al. Effects of low-dose, controlled-release, phentermine plus topiramate combination on weight and associated comorbidities in overweight and obese adults (CONQUER): a randomised, placebo-controlled, phase 3 trial. Lancet 2011; 377: 1341. 
